\title{
Artigo
}

\section{Contribuições de Kraepelin, Bleuler e Bergson para a fenomenologia clínica da esquizofrenia de Minkowski}

\author{
Juliana Pita $\mathbb{1}^{*}$ \\ Virginia Moreira (1)
}

Universidade de Fortaleza, Centro de Ciências da Saúde. Fortaleza, CE, Brasil

\begin{abstract}
Resumo: Este artigo se propõe a apresentar a fenomenologia clínica da esquizofrenia construída pelo psiquiatra Eugène Minkowski por meio de influências teóricas sofridas a partir das ideias de Kraepelin, Bleuler e Bergson. O interesse de Minkowski ao discutir a esquizofrenia é alcançar uma delimitação dessa patologia. Por mais que se remeta constantemente a Bleuler por ter sido seu aluno, é na filosofia de Bergson que encontra uma fonte sólida para aprofundar sua discussão sobre o aspecto estrutural da esquizofrenia. Com essa influência filosófica, é possível compreender a esquizofrenia como perda de contato vital com a realidade, e não como um relaxamento de associações, conforme Bleuler destacava. Concluímos que utilizar a fenomenologia clínica da perda do contato vital com a realidade e a compreensão da esquizofrenia como perda desse contato com o mundo permite apontar um novo direcionamento para estudar esta patologia como uma patologia da intersubjetividade.
\end{abstract}

Palavras-chave: fenomenologia clínica, esquizofrenia, Minkowski.

Eixo norteador da obra do psiquiatra Eugène Minkowski (1885-1972), a alteração da afetividade-contato, ou seja, do meio de acesso à compreensão do humano, é fundadora da compreensão fenomenológica como implicação clínica (Charbonneau, 2010) com a descrição da perda do contato prévio com o mundo na esquizofrenia. Em uma perspectiva da psicopatologia fenomenológica inspirada em Maurice Merleau-Ponty, a esquizofrenia não pode ser definida como um transtorno cognitivo ou perceptivo, mas como um transtorno da experiência préintencional e imediata, estando relacionada aos significados do mundo vivido (Lebenswelt). Disso decorre que o objetivo da psicopatologia fenomenológica é "compreender como a unificação da experiência se realiza ou não mais em nós, e como se manifesta clinicamente naquela [experiência] em que não se realiza mais" (Charbonneau, 2010, p. 65). Com este olhar fenomenológico, entendemos que o processo psicótico na esquizofrenia apresenta falha na unificação da experiência ao condensar a totalidade das nossas experiências no convívio social com os outros, nomeada por Minkowski como "perda do contato vital com a realidade".

O contato vital com a realidade visa muito mais o fundo mesmo, a essência da personalidade viva, em suas relações com o ambiente. E esse ambiente, para frisar novamente, não é nem um conjunto de excitações externas, nem de átomos, nem de forças ou de energias. Não; ele é essa onda móvel que nos

* Endereço para correspondência: julianapitap@gmail.com envolve de todas as partes e que constitui o meio sem o qual não poderíamos viver. (Minkowski, 2004, pp. 133-134)

Minkowski é um dos psiquiatras de destaque na tradição da psicopatologia fenomenológica, sendo conhecido por ter lançado uma trilogia importante para pesquisas psicopatológicas na vertente fenomenológica: La Schizophrènie (1927/2002), Le temps vécu (1933) e Traité de psychopathologie (1966/1999). Trabalhou com Eugen Bleuler (1857-1939), o primeiro psiquiatra a nomear a esquizofrenia como tal, sendo, portanto, profundo conhecedor de suas obras.

Após publicar seu primeiro artigo sobre os textos de Bleuler em 1922, Minkowski decide escrever um livro sobre esquizofrenia, distanciando-se do caminho daquele. Ele não se orienta a partir de um conjunto sempre variável de sintomas, como fazia Bleuler, mas segue em direção ao conceito de estrutura oferecida pela Gestalt. Podemos afirmar que, diferentemente de Bleuler, cuja inspiração era o psiquiatra alemão Emil Kraepelin (1856-1926), Minkowski é influenciado por Edmund Husserl (1859-1938), Henri Bergson (1859-1941) e Karl Jaspers (1883-1969) (Allen, 2002).

Ao iniciar a prática da psicopatologia fenomenológica em 1922, com Ludwig Binswanger (1881-1966), Minkowski aponta para uma mudança na postura do psiquiatra diante de seu paciente. O papel deste profissional não se limita mais apenas a registrar as informações oferecidas pelo paciente e enquadrá-lo em um diagnóstico específico, pois entende que o psiquiatra, com um viés fenomenológico, "penetra a 
realidade desta experiência" (Allen, 2002, p. 18) para apreender de que modo ocorrem as falhas que bloqueiam o fluxo de sua experiência.

O interesse de Minkowski (1927/2002) por esse caminho complexo da discussão da esquizofrenia busca delimitar o conceito. Para isso, necessita partir de pesquisas anteriores sobre a temática, como as de Bleuler, primeiro psiquiatra a descrever a "clínica da esquizofrenia" (p. 28) de forma mais detalhada e rica. Após seu contato com Bleuler, Minkowski (1927/2002) encontra entraves nas proposições teóricas presentes nesses estudos, pois a esquizofrenia era definida como uma doença mental particular e, para o autor, este conceito carece de ampliação.

As ideias bleulerianas facilitam o avanço de Minkowski (1927/2002) em direção a uma "nova orientação psicopatológica" (p. 28) para fundamentar a psiquiatria moderna. Encontramos na esquizofrenia um caminho fértil para compreender estes novos embasamentos psiquiátricos ao destacar os questionamentos sobre os estudos dos mecanismos esquizofrênicos e a análise psicológica do comportamento particular de pacientes esquizofrênicos. Tomando essas duas inquietações como ponto de partida, Minkowski elabora suas pesquisas sobre a patologia.

Este artigo consiste em uma pesquisa teórica e apresenta a evolução do conceito de demência precoce à esquizofrenia e a inspiração de Minkowski na filosofia de Bergson. Tem como objetivo descrever a contribuição de Kraeplin, Bleuler e Bergson para a fenomenologia clínica da esquizofrenia de Eugene Minkowski.

\section{Krapelin e Bleuler: da demência precoce à esquizofrenia}

Kraepelin apresentara um conceito sintético e amplo de demência precoce definindo-o como resultado de um conjunto de formas clínicas particulares, como a catatonia, a hebefrenia e a demência paranoide. $\mathrm{O}$ termo demência precoce utilizado por Kraepelin ainda se restringe à definição desse mesmo conceito desenvolvido pelo psiquiatra franco-austríaco Bénédict Morel (1809-1873), pois aponta para um quadro de empobrecimento intelectual com surgimento após a adolescência ou no início da idade adulta (Pereira, 2000; R. C. B. Silva, 2006).

O conceito de demência precoce de Kraepelin traz um novo problema para o campo psicopatológico, por se tratar da junção de formas clínicas diferentes em um mesmo conceito, entendendo-as de maneira semelhante. Assim, juntam sintomas com características próprias por meio do conceito de demência precoce, o que, para Minkowski (1927/2002), desvaloriza a singularidade de cada sintoma.

Os sintomas são compreendidos por Kraepelin como diferentes entre si, mas direcionam a um mesmo local, ou seja, eles têm algo em comum a dizer sobre um "processo mórbido subjacente, sempre o mesmo" (Minkowski, 1927/2002, p. 101). Surge, então, a necessidade de compreender a riqueza dos diversos sintomas e quadros clínicos da demência precoce como transtorno fundamental.

A demência precoce não deveria ser pesquisada apenas a partir dos sintomas clínicos apresentados pelo paciente, pois não são constantes nem podem oferecer características básicas para essa patologia. Um transtorno fundamental não deve ser estudado por suas bases comuns, os sintomas, mas precisa ser visto por outro ângulo para acessar suas particularidades sem se limitar às variedades de sintomas encontrados na esquizofrenia (Minkowski, 1927/2002).

Além de suas proposições acerca dos sintomas clínicos receberem críticas, Kraepelin também é acusado de negligenciar a análise psicológica na constituição da demência precoce, pois, desde os estudos do psiquiatra francês Jean-Étienne Esquirol (1772-1840), essa análise deve integra qualquer compreensão dos fenômenos psicóticos (Pereira, 2000). Mesmo assim, para Minkowski (1927/2002, 1966/1999), a compreensão psicológica da esquizofrenia é superficial, tendo em vista que os aspectos analisados pela psicologia mais reconhecida da época se limitavam à inteligência, aos sentimentos e à vontade, e essa patologia não consegue ser discutida exclusivamente sob essas três vertentes.

Kraepelin traça uma hipótese psicofisiológica da demência precoce como transtorno da abstração por encontrar um enfraquecimento das motivações emocionais e uma perda da unidade interior, levando o paciente à falha das ideias e à fragilização dos sentimentos. Com o transtorno de abstração, o paciente se torna incapaz de transformar as percepções em ideias mais gerais.

Partindo das questões levantadas por Kraepelin sobre a demência precoce, Bleuler busca esclarecêlas a partir das categorias da psicanálise freudiana. Comentando isso, Pereira (2000) aponta que:

De Jung, ele já recebera a noção, expressa em A psicologia da demência precoce, segundo a qual o que faz a especificidade dessa psicopatologia não é propriamente a qualidade dos complexos, mas a extrema fixação que o sujeito tem a estes, instalando-se uma situação insuportável de absorção de todos os interesses do indivíduo em seu próprio mundo psíquico, isolando-se dos laços afetivos, da vida social e do próprio contato com a realidade. A noção bleuleriana de "esquizofrenia" buscaria, justamente, colocar em relevo aquele que seria o fenômeno nuclear desses estados mentais, a ruptura, a cisão do eu, em função do rompimento dos vínculos associativos que assegurariam um funcionamento unitário da personalidade. (p. 161)

Em 1906, Bleuler começa a utilizar o termo esquizofrenia para definir sua diferenciação das ideias 
de Kraepelin, pois, para aquele, o transtorno não se limita a uma única afecção, mas a um grupo ainda não definido de condições com um núcleo comum. Com esse conceito, Bleuler destaca os sintomas primários como irredutíveis à compreensão psicológica e que possibilitam o aparecimento da patologia (Pereira, 2000; R. C. B. Silva, 2006).Os sintomas primários fazem referência à clivagem das associações entre as funções psíquicas, rompendo a unidade do eu e colocando em jogo a necessidade de restituição da integração perdida a ser apontada pelos sintomas secundários. Estes se referem às tentativas de sustentar um estado psíquico desesperador de ruptura da unidade do eu, como a alteração do fluxo do pensamento, a ambivalência afetiva, os delírios e as alucinações (R. C. B. Silva, 2006).

Bleuler destaca outra diferença entre os sintomas fundamentais e os acessórios. Os primeiros são os que aparecem em todos os níveis e períodos da esquizofrenia: o autismo, a ambivalência afetiva, as alterações da afetividade e os distúrbios das associações. Os sintomas acessórios, que não aparecem necessariamente em todo paciente esquizofrênico ou em todos os estágios dessa patologia, são: delírios, alucinações e outros. Os sintomas primários são definidos a partir da interpretação dos sintomas do paciente e de uma concepção global da patologia (Pereira, 2000; R. C. B. Silva, 2006).

Minkowski (1927/2002), não satisfeito com o caminho para o qual se direcionam as discussões sobre esquizofrenia, assim como Bleuler, segue o olhar psicanalítico, mas conclui que esta seria apenas uma forma de compreender a patologia. Bleuler traça dois aspectos a serem observados na esquizofrenia: $o$ primeiro com um olhar psicoclínico estrutural e o segundo partindo de uma abordagem psicanalítica. Com o olhar psicoclínico, estuda-se a estrutura da personalidade do paciente e determinam-se suas principais características para entender como esses fenômenos se organizam e se reestruturam com a falta de um deles. Com a compreensão psicanalítica, investigam-se os eventos no passado do paciente que podem estar relacionados e afetando seu presente com intuito de delinear o conteúdo psicológico de seus sintomas (Minkowski, 1927/2002).

Seguindo essa explicação, Minkowski (1927/2002) argumenta que:

Os dois lados da noção de Bleuler, intimamente ligados entre si, parecem destinados a seguir, no curso da evolução, direções cada vez mais divergentes. É o aspecto estrutural que eu procuro destacar, por isso, é esse aspecto que, em minha concepção, constitui a pedra angular do problema da esquizofrenia, e até mesmo além, de uma psicopatologia geral do futuro. (p. 30)

Os dois aspectos - psicoclínico estrutural e psicanalítico-, para Minkowski, propõem direcionamentos distintos para entender mais profundamente a esquizofrenia. Considerando o olhar psicanalítico insuficiente, ele não se esquece da existência dos sintomas que necessitam de compreensão psicológica, enfatizando que são justamente estes que precisam ser aprofundados. $\mathrm{O}$ aspecto estrutural é selecionado por Minkowski para embasar o novo olhar fenomenológico que se estabelece em suas pesquisas relativas à esquizofrenia naquele momento, pois este é entendido por ele como o melhor direcionamento para investigar o vivido esquizofrênico de seus pacientes.

Seja qual for o termo utilizado para se referir a essa patologia - demência precoce com Kraepelin ou esquizofrenia com Bleuler -, o objetivo de Minkowski (1927/2002) é clarificar o transtorno fundamental da esquizofrenia sem se deter a uma função do psiquismo a que este transtorno deva remeter, pois, para ele:

O transtorno essencial não altera uma ou mais faculdades mentais, independentemente de sua ordem na hierarquia das funções, mas reside bem entre elas [funções], no "espaço intersticial". Contudo todas essas expressões não são, no fundo, apenas uma constatação do fato, uma designação de desordem particular que apresentam os dementes precoces ou os esquizofrênicos. (p. 103)

A esquizofrenia se impõe a ela mesma, tornando desnecessária ou irrelevante a definição de sua origem orgânica ou psíquica. Nesse caminho, a ideia de Minkowski (1927/2002) é não se limitar a tentar identificar qual função do psiquismo se altera e origina a esquizofrenia, pois, já com Kraepelin, falava-se em uma "orquestra sem maestro" (p. 104). O olhar fenomenológico de Minkowski possibilita uma compreensão da estrutura do vivido esquizofrênico. Para ilustrar, destacamos uma metáfora construída por Minkowski (1927/2002):

Um prédio é feito de tijolos e cimento, os tijolos podem se esmigalhar, o cimento também; o edifício não existe mais; contudo, trata-se nos dois casos de situações diferentes; as ruínas não serão as mesmas, não terão nem o mesmo aspecto, nem 0 mesmo valor; seria mais fácil reconstruir uma nova casa com os tijolos intactos do que com a poeira. (pp. 104-105)

Com esta metáfora da destruição de um prédio, Minkowski (1927/2002) nos diz que ele pode ser destruído de diversas formas, e seus diferentes materiais estruturais, como tijolo e cimento, podem se tornar poeiras distintas. Não buscamos definir a origem da queda do prédio, mas estamos diante de dois modos completamente singulares de como a queda aconteceu. Com isso, se algo da estrutura do prédio permanece preservado, torna-se mais fácil construí-lo com os restos dos tijolos do que com a poeira do cimento.

Utilizando essa metáfora para pensar os processos envolvidos na elaboração da esquizofrenia, o desejo 
pode se manter; o que não há é a obrigatoriedade ou a necessidade de definir o lugar de sua origem. Entende-se que não podemos saber como se constitui o processo esquizofrênico destacando, por exemplo, as falhas, como encontradas no exemplo do desmoronamento do prédio ou no enfraquecimento intelectual do esquizofrênico.

Com um olhar fenomenológico, não buscamos unicamente a origem da esquizofrenia, muito menos tentar fundir diversas formas clínicas em uma única nomenclatura, como já fazia Kraepelin com a demência precoce. A constante procura por definições limitantes destacadas pela ciência médica não auxilia na compreensão dos mais variados vividos esquizofrênicos, pois, com isso, sacrifica-se a experiência vivida por cada paciente em seus diversos modos esquizofrênicos.

\section{A filosofia de Bergson como inspiração para Minkowski}

Nosso objetivo, aqui, é identificar as relações entre Minkowski e a filosofia de Bergson, assim como as características gerais de seu pensamento para, posteriormente, discutir o conceito de perda do contato vital com a realidade na esquizofrenia. Por mais que remeta constantemente ao trabalho psiquiátrico de Bleuler por ter sido seu aluno, é na filosofia de Bergson que Minkowski encontra uma fonte sólida para aprofundar sua discussão fenomenológica sobre o aspecto estrutural da esquizofrenia. Com essa influência filosófica, Minkowski compreende a esquizofrenia como a perda de contato vital com a realidade, e não como um relaxamento de associações, tal como Bleuler a entende. Com a ideia de perda de contato, ou seja, a perda da dinâmica das relações sociais, desvendam-se as manifestações características dessa patologia, destacando que todos os sintomas, sejam acessórios ou primários, estão direcionados a um ponto em comum - a perda do contato vital com a realidade. Para Minkowski (1927/2002):

Um dos maiores filósofos contemporâneos, Bergson nos lembrou, mais uma vez, que um aspecto de nossa vida e não o menos importante fugia inteiramente ao pensamento discursivo. Os dados imediatos da consciência, os mais essenciais, pertencem a essa ordem dos fatos. Eles são irracionais. Não são menos importantes em nossa vida por causa disso. Não existe nenhum motivo em sacrificá-los em razão da precisão. É necessário, pelo contrário, tentar apreendê-los a partir do vivido. (p. 105)

Minkowski (1927/2002) reconhece a grande importância de olhar para esses dados imediatos da consciência a partir do vivido, e não pelo enfoque científico. Embora não desvalorize as fundamentais contribuições oferecidas pela obra bleuleriana, pois fora ela quem lhe ensinara sobre psiquiatria, ele continua sua investigação por uma via diferente, a estrutural, por fazer mais sentido no esclarecimento de seus questionamentos a respeito da patologia discutida aqui. Para isso, ele destaca a necessidade da psiquiatria moderna descobrir mais sobre a esquizofrenia e sua relação com as experiências de quem a vivencia, encontrando o caminho para falar sobre os fenômenos essenciais da vida do homem nas obras de Bergson.

O filósofo francês Henri Bergson se dispõe a discutir o impulso originário da vida questionando o significado de existir. Constrói essa ideia partindo de críticas às teorias deterministas do homem, como o mecanicismo e o finalismo, nas quais são propostas as reduções da existência humana em leis previsíveis e manipuláveis, buscando como ponto de partida a duração do tempo. Afirma que:

O que existe é o fluir de uma continuidade. Se a nossa existência fosse constituída por estados separados cuja síntese teria que ser feita por um "eu impassível", não existiria para nós duração. Porque um eu que não muda, não dura, e um estado psicológico que permanece idêntico a si próprio, enquanto não é substituído pelo estado seguinte, igualmente não têm duração. (Bergson, 1889/2013, pp. 43-44)

Caso a existência humana fosse previsível e controlável, não haveria duração de um tempo e, consequentemente, esse homem seria estático, não haveria mudança e se encontraria em um estado psicológico paralisado. O psicológico, para Bergson (1889/2013), é constituído pelo tempo, já que "nossa personalidade se desenvolve, cresce e amadurece sem cessar. Cada um dos momentos é algo novo . . não é apenas algo novo, mas algo imprevisível" (p. 45). O imprevisível se refere a um "arranjo de elementos antigos" (p. 65), algo de que nunca tivemos percepção, pois cada momento é uma história que se desenvolve e "cada um deles é uma espécie de criação" (p. 46) que sempre nos modifica. Com isso, Bergson aponta para a inexistência de uma lei biológica idêntica para todos.

Discutindo o impulso originário da vida, percebe-se que:

Nenhuma das duas teses, nem aquela que afirma, nem aquela que nega a possibilidade de algum dia se produzir quimicamente um organismo elementar, pode invocar a autoridade da experiência. Ambas são inverificáveis; a primeira, porque a ciência ainda não deu sequer um passo para a síntese química de uma substância viva, a segunda, porque não existe nenhum meio pensável de provar experimentalmente a impossibilidade de um fato. (Bergson, 1889/2013, p. 70)

Para ele, de um lado, nossas vidas são guiadas por pensamentos discursivos. Não que eles tenham 
menos importância, mas, seguindo apenas o caminho pautado pelo pensamento racional, muitas vezes menosprezamos nossos sentimentos. Até por volta de 1900, devido à forte influência das ideias de Descartes mostrando o homem como um ser pensante, a loucura é vista como sinônimo de "perda da razão" (Minkowski, 1927/2002, p. 154), e esse é o ponto de vista da maioria dos psiquiatras clássicos.

Minkowski (1927/2002) destaca que o homem sonha ao dormir, e o esquizofrênico, embora não esteja dormindo, expressa sua vida íntima do mesmo modo como o sonhador. Para compreender melhor esse mecanismo sonhador na esquizofrenia, Minkowski (1927/2002) recorre à explicação de Bleuler sobre o que significa o autismo: "os esquizofrênicos mais avançados que não têm mais nenhuma relação com a ambivalência vivendo em um mundo que é apenas deles" (p. 165), como alguém que está sonhando. Pereira (2004) assinala que:

A psicopatologia de Bleuler, diferentemente da ênfase descritiva e classificatória de Kraepelin, fundava-se na busca da delimitação precisa do "transtorno gerador" do distúrbio mental. Tratava-se, sobretudo, de identificar a perturbação psicopatológica fundamental sobre a qual se instala o quadro clínico observável. Sob essa perspectiva, os sintomas primários da esquizofrenia exprimiriam uma profunda alteração da personalidade, derivada do conjunto de reações mentais ao transtorno gerador. Este elemento psicopatológico primário era, segundo Bleuler, claramente identificável na esquizofrenia: a desagregação, a clivagem da personalidade. (pp. 126-127)

Visto que a esquizofrenia é compreendida por Bleuler por meio de seus sintomas, como a ideação, a afetividade e a volição do doente, no momento de suas investigações, com o surgimento das primeiras tentativas de definição do autismo, os fatores de compreensão começam a se deslocar e um papel muito importante passa a ser ocupado pelas relações do homem com o meio no qual ele se insere. A falta de diretriz e a ausência de contato afetivo dos pacientes esquizofrênicos abrem portas para o surgimento de outra forma de compreensão dessa patologia (Minkowski, 1927/2002; 1999/1966), a qual se direciona para discutir a esquizofrenia como uma patologia da intersubjetividade, que é vivida na relação do homem com o mundo (Souza, Callou, \& Moreira, 2013). Portanto,

trata-se de uma compreensão do adoecimento psicopatológico que não se apresenta a partir de um pensamento reflexivo e externalizado, mas como uma coexperiência, em que temos o transtorno e também a experiência do sujeito adoecido. (Souza et al., 2013, p. 195)
A fragmentação da experiência psíquica em pensamento, afetividade e memória oferece, para Minkowski, uma forma artificial de compreensão do processo psíquico como um todo na esquizofrenia. Buscando a descrição da experiência vivida tal como ela se dá, a fenomenologia oferece ferramentas para isso. Opondo-se ao reducionismo objetivista dos fenômenos psíquicos, o método fenômeno-estrutural de Minkowski busca o encontro mais próximo possível com o humano. Não objetiva apenas descrever a experiência vivida do indivíduo em sofrimento mental, como feito por Jaspers em Psicopatologia geral (1913), mas se propõe a relacionar tais experiências com uma estrutura organizadora dessas alterações patológicas (Pereira, 2004). Aqui nos referimos à estrutura na qual "qualidades expressivas do espaço e do tempo vividos assume um dos papéis fundamentais na apreciação das características psicopatológicas e, mais amplamente, psicológicas da personalidade" (Barthélémy, 2012, p. 96). Entende-se que:

É nessa perspectiva, também, que Minkowski assume resolutamente a concepção de que a psicopatologia constitui uma psicologia do patológico, e não uma patologia do psicológico. Essa última proposição obriga o clínico e o pesquisador a recorrerem a uma incerta referência à noção de "normalidade", concebida como padrão absoluto a partir do qual se definem os desvios mórbidos da vida mental. (Pereira, 2004, p. 128)

Com essas ideias, Minkowski (1927/2002) se distancia dos conceitos de Bleuler e traça um caminho sobre o transtorno essencial da esquizofrenia definindo-o como a perda do contato vital com a realidade. Essa condição de perda do contato permite a instalação de um modo de estar patológico e o aparecimento de sintomas secundários:

Ao contrário, ao conhecer a experiência humana como intrinsecamente pática, ou seja, fundada sobre o pathos da paixão e do sofrimento, a psicopatologia tem por tarefa a descrição de formas singulares de existência e de estar-no-mundo. Com tal atitude teórica e metodológica, Minkowski aborda o fenômeno esquizofrênico visando exprimir o fundo existencial sobre o qual este transcorre, antes de realizar um recenseamento de sintomas e de alterações das faculdades da alma. (Pereira, 2004, p. 128)

O conceito apresentado por Minkowski remete a um aspecto da vida do homem que não é, até então, destacado: o campo irracional da vida, suas vivências e experiências. $\mathrm{O}$ esquizofrênico perde a possibilidade de dinâmica dos contatos com o campo sensorial, quer dizer, de troca de experiências com as outras pessoas 
e com tudo que nos faz sentir vivos e pertencentes ao mundo. $\mathrm{O}$ esquizofrênico perde o contato com as regras das relações sociais que são compartilhadas no senso comum. Minkowski (1927/2002) aponta que

os cegos, os mutilados, os paralíticos podem viver em contato bem mais íntimo com o meio que os indivíduos cuja vista está intacta e que tem seus quatro membros; por outro lado, os esquizofrênicos perdem esse contato, sem que seu aparelho sensitivo-motor, sem que sua memória e sua inteligência estejam alteradas. O contato vital com a realidade visa bem mais o fundo, a essência da personalidade viva, em suas relações com o meio. E este meio, de novo, não é aqui nem um conjunto de excitações externas, nem de átomos, nem de forças ou de energia. Não, ele é essa inundação em movimento que nos envolve de todas as partes e que constitui o meio sem o qual nós não saberíamos viver. (p. 106)

Destacamos a influência da filosofia bergsoniana ao compreender que o homem vivencia essa inundação em movimento do que está ao nosso redor, pois Minkowski (1927/2002) apresenta os eventos vividos como "ilhotas" (p. 106) que penetram nesse homem e vão compondo sua vida íntima, seu aspecto mais pessoal, seus sentimentos e seus atos. Assim, a relação entre o homem e a realidade acontece nessa invasão do mundo em sua vida, possibilitando a construção de suas experiências.

O contato vital com a realidade depende da relação entre homem e mundo, dessa inundação em movimento, embora esse conceito não seja tão novo. Inicialmente, Minkowski (1927/2002) encontra fundamentos com o psiquiatra e neurologista francês Pierre Janet (1859-1947) e sua teoria da psicastenia, na qual já se discute a função do real para o homem e se destacam pontos em comum com o que venha a ser o contato vital com a realidade. Mas o fortalecimento da ideia de que identificamos nos pacientes esquizofrênicos essa perda do contato da realidade acontece a partir da influência que Minkowski encontrou nas leituras dos textos filosóficos de Bergson. Sem esquecer que seu trabalho foi bastante afetado por Bleuler e, a partir da ideia deste, de que encontramos nos esquizofrênicos uma perturbação profunda de suas relações com o mundo exterior. Para Minkowski (1927/2002), a ressalva feita a Bleuler é que ele se prende ao estudo dos sintomas e elementos dessa afetação e insiste na perda do contato com a realidade - o autismo.

De modo diferente do de Bleuler, os pilares da clínica da esquizofrenia, as condições autísticas, são delimitadas por Minkowski de duas maneiras: (1) autismo rico: caracterizado pela criação de um mundo imaginário; e (2) autismo pobre: apresenta a perturbação esquizofrênica em estado puro, parada do élan vital. Bergson elabora o conceito de élan ou impulso vital e a ideia de uma evolução criadora a partir da biologia
(A. J. Silva, 2006) e define que a vida está em constante movimento, sendo "resultado natural da luta entre o espírito e a matéria" (p. 1).

Com Minkowski, a perda do contato é vista como transtorno gerador da esquizofrenia. Já para Bleuler, a perda do contato não é um fator essencial da vida ao defender a busca por uma base orgânica para a esquizofrenia, $o$ que revela que ele não se desprendeu totalmente de uma influência associacionista (Pereira, 2004).

A perda do contato vital com a realidade na esquizofrenia aponta para o fato da perturbação esquizofrênica se apoiar na ruptura radical com o mundo humano, ou seja, com o laço social. O esquizofrênico se inunda de uma vivência de absurdos que lhe impõe uma reconstrução forçada e artificial do sentido de sua existência, de seu corpo e de seu estar-no-mundo (Pereira, 2004).

Mas até que ponto o conceito de perda do contato vital com a realidade oferece subsídios para compreender a esquizofrenia? Esse conceito de Minkowski é oriundo, principalmente, de sua tentativa de unir a clínica da escola suíça às ideias filosóficas de Bergson, entendendo que a psicologia e a psicopatologia necessitam de contribuições sobre o conhecimento humano advindas de uma filosofia. A principal colaboração de Bergson para Minkowski compreender fenomenologicamente a esquizofrenia se dá pela "oposição fundamental entre a inteligência e o instinto" (Minkowski, 1927/2002, p. 111) que o filósofo propõe como meio de compreensão do ser humano. Para Minkowski (1927/2002),

A psicopatologia não poderia estar direcionada a questionar se as concepções de Bergson não eram suscetíveis para projetar um novo brilho sobre os problemas diante dos quais as noções da psicologia corrente teriam fracassado até ali. Tratava-se de ver, ao mesmo tempo, até qual ponto os fatos psicopatológicos podiam ser chamados para confirmar os dados colocados em evidência pela intuição genial do grande filósofo. (p. 112)

Com o olhar oriundo de Bergson, pode-se pensar em alcançar a patologia tal como ela se mostra e percorrer o caminho que nem a psicologia, nem a psiquiatria traçam na compreensão da complexidade que envolve a esquizofrenia, pois elas têm acesso apenas aos aspectos psicológicos. O olhar de Minkowski excede este único aspecto, pois o psiquiatra entende que é fundamental considerar que os esquizofrênicos sempre se encontram em constante relação com o mundo. Para compreendê-los, é imprescindível entender e descrever a relação entre os dois, homem e mundo.

$\mathrm{Na}$ época de suas pesquisas, Minkowski constata que as funções mentais elementares permanecem intactas na esquizofrenia, sendo identificados apenas uma inteligência menos atenta e comportamentos semelhantes ao que é reconhecido como característico de outras 
patologias, como o delírio incoerente e atos bizarros. Se isso é assim, então o que diferencia a esquizofrenia de outra patologia? Bergson e a oposição fundamental entre a inteligência e o instinto ajudam a esclarecer os questionamentos de Minkowski.

A inteligência não admite o imprevisível, pois, ao rejeitar toda criação, ela se limita ao que se repete. É justamente dessa diferença que Minkowski está à procura. Não se restringindo apenas às falhas caracterizadoras da existência esquizofrênica, mas voltando-se também para aquilo que "permanece intacto" (Minkowski, 1927/2002, p. 115), o autor se direciona a uma comparação entre esquizofrenia e deficiência intelectual, exclusivamente com o então chamado paralítico geral:

Eu pergunto a um paralítico geral que chegou a um período de senilidade: “onde você está?". Ele responde: "aqui". Por medo de que isso possa ter sido uma manifestação puramente verbal e automática de sua parte, eu insisto: "mas aqui onde?". O doente bate o pé, para indicar a localização onde ele se encontra, ou aponta com seu dedo a fim de indicar o quarto que ele ocupa. "Mas aqui", ele nos diz, parecendo mesmo surpreso e irritado com nossa insistência. (Minkowski, 1927/2002, pp. 115-116)

Nesse caso, trata-se de uma manifestação encontrada em doentes com esse tipo de deficiência intelectual. Com o esquizofrênico, a situação seria um pouco diferente, pois, se ele responde à questão sobre sua localização, diz que "não se percebe neste lugar ocupado por ele, não se percebe em seu corpo, o 'eu existo' não tem um sentido preciso para ele" (Minkowski, 1927/2002, p. 116). Minkowski (1927/2002) chama atenção para o fato de que o paralítico se apresenta de forma completamente desorientada no espaço. Já o esquizofrênico sabe onde ele está, mas o "eu aqui não tem mais sua tonalidade habitual" (p. 117).

A partir dessa perspectiva, o questionamento de Minkowski se volta a entender como o esquizofrênico consegue construir seu comportamento baseado em fatores objetivos, mesmo com dificuldade em sentir seu movimento no mundo. Além disso, para o autor, a problematização da esquizofrenia se apoia também na teoria bergsoniana do movimento, a qual apresenta o tempo e o espaço vinculados. Trata-se de compreender, então, como é vivenciada a duração do tempo em um "funcionamento normal e em seus desvios patológicos" (Minkowski, 1927/2002, p. 119). No paralítico geral, a duração temporal é esquecida, não se sabe mais quais são os dias, as semanas nem os meses. O que permanece para o paralítico é apenas a lembrança da ocorrência de determinados fatos, mas ele não se recorda mais do início ou do término deste acontecimento. O paralítico experiencia o mundo como se estivesse em um "único oceano em movimento" (p. 122).
$\mathrm{Na}$ experiência esquizofrênica, deparamos com uma experiência diferente, pois o doente perde o contato com todas as coisas que o circundam e não se vê como em um oceano em movimento, como citado, mas como um homem paralisado no tempo e sente que tudo está imobilizado ao seu redor. Na fala de um esquizofrênico:

Eu perdi o contato com todas as coisas. As noções de valor e de dificuldade das coisas desapareceram. Não há mais nada de comum entre elas e eu, não posso mais me abandonar. É uma fixação absoluta em torno de mim. Eu tenho ainda menos mobilidade para o futuro do que para o presente e o passado. Existe em mim como um tipo de rotina que não permite visualizar o futuro. O poder criativo está suprimido em mim. Eu vejo o futuro como repetição do passado. (Minkowski, 1927/2002, p. 122)

A passagem descrita se refere à fala de um paciente esquizofrênico, acompanhado por Minkowski, que passa dias em sua cama totalmente paralisado, em estado de inércia e, ao se levantar, sente-se guiado por alucinações auditivas lhe ordenando a atear fogo em suas roupas para ver se consegue encontrar seu eu. Com base nesse caso, Minkowski (1927/2002), mais uma vez, sugere a perda do contato com a realidade como o caminho mais indicado para melhor compreender a experiência esquizofrênica.

Nessa patologia, encontramos pacientes descrevendo suas ideias de forma paralisada, dando a impressão de estarem congelados, como "estátuas" (Minkowski, 1927/2002, p. 123) e, por estarem vivendo experiências sem movimento, parece faltar uma "tendência à realização" (p. 123). Identificamos, na esquizofrenia, um estado estático e "suas reações carregam também, geralmente, a marca dessa paralisação mórbida e nós a encontramos até nos movimentos estereotipados que, no fundo, são apenas um eterno recomeço, sem nenhuma progressão" (Minkowski, 1927/2002, p. 123). Encontramos uma pessoa paralisada, sem andar para trás, muito menos para frente, com uma sensação de congelamento temporal e espacial.

De um lado, a esquizofrenia é definida, por Bleuler, como demência afetiva para designar uma separação entre seus sintomas: o declínio esquizofrênico e a demência intelectual. De outro, essa patologia é entendida por Minkowski como déficit pragmático, por não se referir a uma verdadeira demência no sentido de haver falha intelectual. Com esses caminhos opostos e sofrendo influências filosóficas, principalmente de Bergson, Minkowski define o enfraquecimento do contato vital e da afetividade como o elemento necessário para caracterizar a esquizofrenia.

\section{Considerações finais}

Diversas definições sobre a esquizofrenia foram galgadas ao longo da história da psiquiatria com Kraepelin, Bleuler, entre outros. Destacamos a importância do 
conceito de demência precoce de Kraepelin como um novo problema para o campo psicopatológico, já que se trata da união de diversas formas clínicas em um único conceito. Além das contribuições diretas das ideias de Bleuler, Minkowski (1927/2002) segue em direção a uma nova fundamentação para a psicopatologia moderna por intermédio das contribuições filosóficas de Bergson, que possibilitam a elaboração do conceito de perda do contato vital na esquizofrenia.

Concluímos que direcionarmo-nos rumo ao desenvolvimento do conceito de contato vital com a realidade e da compreensão da esquizofrenia como perda desse contato com o mundo permite reconhecer e apontar um novo direcionamento para estudar essa patologia com uma lente fenomenológica e possibilitar novas intervenções clínicas. A fenomenologia da esquizofrenia fundamentada por Minkowski enquanto perda do contato vital com a realidade é um passo adiante e uma evolução do conceito de demência precoce, ao ser definida como o transtorno gerador dessa patologia. Entendemos que Minkowski situa a esquizofrenia na interseção entre o sujeito que tem esse diagnóstico e o mundo, permitindo a possibilidade de discutir a esquizofrenia como uma patologia da intersubjetividade.

\title{
The contributions of Kraepelin, Bleuler and Bergson to Minkowski's clinical phenomenology of schizophrenia
}

\begin{abstract}
This article presents the clinical phenomenology of schizophrenia constructed by the psychiatrist Eugène Minkowski through theoretical influences from the ideas of Kraepelin, Bleuler and Bergson. Minkowski's interest in discussing schizophrenia is to be able to determine this pathology. Although references are constantly made by him to Bleuler for having been his student, it is in Bergson's philosophy that he finds a solid source to further his discussion of the structural aspect of schizophrenia. With this philosophical influence, it is possible to understand schizophrenia as a loss of vital contact with reality and not as a relaxation of associations, as Bleuler pointed out. We conclude that using the clinical phenomenology of the loss of vital contact with reality and the understanding of schizophrenia as a loss of this contact with the world allows for a new direction to study this pathology as a pathology of intersubjectivity.
\end{abstract}

Keywords: phenomenology clinical, schizophrenia, Minkowski.

\section{Les contributions de Kraepelin, Bleuler et Bergson à la phénoménologie clinique de la schizophrénie de Minkowski}

Résumé : Le présent article se propose à discuter la phénoménologie clinique de la schizophrénie construite par le psychiatre Eugène Minkowski à travers les influences théoriques issues des idées de Kraepelin, Bleuler et Bergson. L'intérêt de Minkowski lorsqu'il élabore une discussion sur la schizophrénie est de parvenir à avoir une délimitation de cette pathologie. Même si on reconnaît qu'il mentionne constamment Bleuler, vu qu'il était son élève, c'est dans la philosophie de Bergson qu'il trouve une source solide pour approfondir sa discussion sur l'aspect structurel de la schizophrénie. Avec cette influence philosophique, il est possible de comprendre la schizophrénie comme une perte de contact vital avec la réalité et non comme une relaxation d'associations, comme l'a soulignée Bleuler. Nous concluons que l'usage de la phénoménologie clinique de la perte de contact vital avec la réalité et la compréhension de la schizophrénie comme une perte de ce contact avec le monde nous permet de souligner une nouvelle direction d'études de cette pathologie comme une pathologie de l'intersubjectivité.

Mots-clés: phénoménologie clinique, schizophrénie, Minkowski.

\section{Contribuciones de Kraepelin, Bleuler y Bergson a la fenomenología clínica de la esquizofrenia de Minkowski}

Resumen: El presente artículo se propone presentar la fenomenología clínica de la esquizofrenia construida por el psiquiatra Eugène Minkowski por medio de influencias teóricas sufridas a partir de las ideas de Kraepelin, Bleuler y Bergson. El interés de Minkowski al elaborar una discusión de la esquizofrenia es alcanzar una delimitación de esta patología. El autor alude constantemente a Bleuler por haber sido su alumno, pero en la filosofía de Bergson encuentra una fuente sólida para profundizar en su discusión sobre el aspecto estructural de la esquizofrenia. Con esta influencia filosófica, es posible comprender la esquizofrenia como la pérdida de contacto vital con la realidad y no como una relajación de asociaciones, tal como Bleuler destacaba. Concluimos que utilizar la fenomenología clínica de la pérdida del contacto vital con la realidad y la comprensión de la esquizofrenia como pérdida de este contacto con el mundo permite apuntar un nuevo direccionamiento para estudiarla como una patología de la intersubjetividad.

Palabras clave: fenomenología clínica, esquizofrenia, Minkowski. 


\section{Referências}

Allen, D. F. (2002). Préface. In E. Minkowski, La schizophrénie (pp. 11-23). Paris: Petite Bibliothèque Payot. (Trabalho original publicado em 1927)

Barthélémy, J.-M. (2012). Origem e contexto de emergência da noção de estrutura em psicopatologia fenômenoestrutural: evolução do conceito, seu lugar e suas implicações nas práticas clínicas contemporâneas. Psicopatologia Fenomenológica Contemporânea, 1(1), 88-105.

Bergson, H. (2013). Essai sur les données immediate de la conscience. Paris: Flammarion. (Trabalho original publicado em 1889)

Charbonneau, G. (2010). Introduction à la psychopathologie phénoménologique: fondements et principes généraux; corporéité et mienneté; névroses et personnalités pathologiques; intersubjectivité. Paris: MJW Fédition.

Jaspers, K. (1987). Psicopatologia geral. Rio de Janeiro, RJ: Atheneu. (Trabalho original publicado em 1913)

Minkowski, E. (1999). Traité de psychopathologie. Le Plessis-Robinson: Institut Sythélabo. (Trabalho original publicado em 1966)

Minkowski, E. (2002). La schizophrénie. Paris: Petite Bibliothèque Payot. (Trabalho original publicado em 1927)

Minkowski, E. (2004). A noção de perda de contato vital com a realidade e suas aplicações com a realidade e suas aplicações em psicopatologia. Revista Latinoamericana de Psicopatologia Fundamental, 7(2), 130-146.

Pereira, M. (2000). Bleuler e a invenção da esquizofrenia. Revista Latinoamericana de Psicopatologia Fundamental, 3(1), 158-163.

Pereira, M. (2004). Perda do contato vital com a realidade na esquizofrenia, segundo Eugène Minkowski. Revista Latinoamericana de Psicopatologia Fundamental, $7(2), 125-129$.

Silva, A. J. (2006). O impulso vital enquanto princípio explicativo da evolução no pensamento bergsoniano. Revista Eletrônica Existência \& Arte, 2(2), 1-6.

Silva, R. C. B. (2006). Esquizofrenia: uma revisão. Psicologia USP, 17(4), 263-285.

Souza, C., Callou, V., \& Moreira, V. (2013). A questão da psicopatologia na perspectiva da abordagem centrada na pessoa: diálogos com Arthur Tatossian. Revista da Abordagem Gestáltica, 19(2): 189-197.

Recebido: $11 / 01 / 2018$

R1: $19 / 02 / 2019$

R2: $19 / 09 / 2019$

Aprovado: 15/05/2020 